\title{
TREATMENT METHODS OF AVOIDANT/RESTRICTIVE FOOD INTAKE DISORDER - REVIEW WITH THERAPEUTIC IMPLICATIONS
}

\author{
Tamás Dömötör Szalai ${ }^{1}$, Melinda Cserép ${ }^{2}$
}

\author{
${ }^{1}$ Semmelweis University, \\ Institute of Behavioural Sciences, Budapest, Hungary \\ ${ }^{2}$ Semmelweis University, \\ Department of Pediatrics No. I, Budapest, Hungary
}

\begin{abstract}
Background: The introduction of Avoidant/Restrictive Food Intake Disorder (ARFID) have refined childhood and adolescent eating disorders, however it meant a significant change in the diagnostics. Hardly anything is known about its effective interventions and there is a lack of specific treatment guidelines. Thus, our aim was to review the risk factors, assessment methods, and chiefly the treatment methods of ARFID to support its clinical management and psychotherapy. Method: The reviewing process was conducted in two steps, with the primary focus on the literature since the introduction of ARFID using the term of 'avoidant/restrictive food intake disorder' with dates 2012 -2015. The PRISMA flow algorithm was applied to filter results. Results and discussion: Assessment methods involve structured DSM-V interview, supplemented with BryantWaugh's diagnostic guideline, and the Children's Eating Disorder Examination-Questionnaire, or the Eating Disturbances in Youth-Questionnaire. The heterogeneous treatment shall fit the patients' and families individual needs, and the different presentations ARFID (e.g. sensory-based selective eating, of chocking or vomiting phobia and interactional difficulties). A combination of medical treatment with the primary focus on the weight recovery, nutritional management, and psychotherapeutic interventions are suggested; in children parents should be involved. Behavior therapy with exposure, systematic desensitization, CBT with cognitive restructuring, anxiety management, and family based interventions seemed to be the most useful psychotherapeutic interventions. Conclusions: Studies should start assessing the effectiveness of different treatment approaches based on longitudinal researches to describe strict evidence-based guidelines for each presentations of ARFID.
\end{abstract}

Key words: avoidant/restrictive food intake disorder, assessment, treatment, review 


\section{Introduction}

The Diagnostics of Avoidant/Restrictive Food Intake Disorder

Avoidant/Restrictive Food Intake Disorder (ARFID) is a new type of eating disorder freshly introduced by the DSM-5 [1]. Its diagnosis unites and extends the former categories of Eating Disorders, Feeding and Eating Disorders of Infancy or Early Childhood and Somatoform Disorders characterized by phobic food avoidance [2]. The introduction of ARFID specified the formerly not otherwise classified eating disorders of young people with medical and psychological comorbidities [3]. It refines the definition of childhood and adolescent eating disorders reflecting their clinical expression across the developmental span [3], and also offers mutually exclusive criteria from other eating disorders [1]. Thus ARFID mean a substantial improvement in the diagnostics, but as it is different in its many features from classical eating disorders, the classification of ARFID opens up several questions with regard to the proper assessment and treatment. Hay and colleagues [2] underlined the lack of clinical guidelines in ARFID, therefore urged the development of specific assessment and therapeutic guidance. The DSM-5 [1,4] criteria of ARFID are the following:

A. An eating or feeding disturbance (e.g., apparent lack of interest in eating or food; avoidance based on the sensory characteristics of food; concern about aversive consequences of eating) as manifested by persistent failure to meet appropriate nutritional and/or energy needs associated with one (or more) of the following:

1. Significant weight loss (or failure to achieve expected weight gain or faltering growth in children).

2. Significant nutritional deficiency.

3. Dependence on enteral feeding or oral nutritional supplements.

4. Marked interference with psychosocial functioning.

B. The disturbance is not better explained by lack of available food or by an associated culturally sanctioned practice.

C. The eating disturbance does not occur exclusively during the course of anorexia nervosa or bulimia nervosa, and there is no evidence of a disturbance in the way in which one's body weight or shape is experienced.

D. The eating disturbance is not attributable to a concurrent medical condition or not better explained by another mental disorder. When the eating disturbance occurs in the context of another condition or disorder, the severity of the eating disturbance exceeds that routinely associated with the condition or disorder and warrants additional clinical attention.

The diagnosis shall specify if the disorder is in remission, when the criteria are not fulfilled for a sustained period after meeting full criteria of ARFID [1]. The most important exclusion criteria are: the presence of body image disturbance, culturally endorsed traditions, and medical problems or other psychiatric 
disorders in the symptoms' background [5]. Therefore, ARFID should be differentiated from gastrointestinal diseases, food allergies, intolerances, neurological, structural or congenital disorders, autisms spectrum disorders (ASD), specific phobias, social anxiety or other anxiety disorders, obsessive-compulsive disorder, anorexia nervosa, schizophrenia spectrum disorders, factitious disorder or its imposed on another type, and from reactive attachment disorder [1]. Zucker and colleagues [6] suggest refining the diagnosis of ARFID with the precise definition of its subgroups (e.g., deficits in executive or in oralmotor functioning). Feeding and eating disorders are often conceptualized exclusively by the child's disturbance, although child-caregiver interactions have a strong impact on their development and maintenance [7,8]. As childhood feeding disorders are often relational disorders, Davis and colleagues [9] suggested applying a multiaxial diagnosis that involves the child, the parent, their relationship, the nutritional or feeding context, and the disorders' severity to enable proper treatment plan in each childhood eating or feeding disorder.

\section{Characteristics of patients with ARFID}

As ARFID is basically defined by restriction or avoidance of food resulting to negative nutritional or energy balance and at least one clinically relevant consequence, the simple but well defined diagnostics may be the reason of its high frequency in children [10]. The disorder mostly begins in infancy or in childhood around the age of $8-13$, with high $3.2 \%$ prevalence in this age group, causing weight loss, growth impairment, difficulties in social life and school attendance [11]. Associated selective eating pattern may persist to adulthood [1]. Although epidemiological data are heterogeneous indicating $13-32 \%$ prevalence of ARFID in young eating disorder patients $[5,11,12]$, according to most studies approximately $14 \%$ of all eating disorder patients [3, $10]$ and $5-14 \%$ of child gastroenterology patients with eating disorder symptoms can meet the criteria of ARFID [13]. This means that every seventh patient must face with ARFID; while $63 \%$ of children with feeding problems can meet one or more of its criteria: insufficient growth in 19.7\%, dependence on supplements in $54.5 \%$, nutritional deficiency in $21.5 \%$ [12]. Patients presenting ARFID symptoms are often considered firstly as medically ill then the focus switches soon to the mental illness [5].

ARFID poses risk to other eating disorders, most of all anorexia nervosa [14], although it can be distinguished from classical eating disorders by the lack of body image disorder. In spite of this, $21 \%$ of ARFID patients have preoccupation with somatic concerns, although differently from the general symptoms of body image disorder [5]. According to Forman and colleagues [15] ARFID patients are more often males than in anorexia or bulimia $(29 \%$ vs. $15 \%$ vs. $6 \%$ ), are usually younger ( 12.9 vs. 15.6 vs. 16.5 years), and more characterized by comorbid medical conditions $(55 \%$ vs. $10 \%$ vs. $11 \%)$ and anxiety disorders ( $58 \%$ vs. $35 \%$ vs. $33 \%$ ), but less affected by mood disorders 
(19\% vs. $31 \%$ vs. $58 \%$ ). ARFID patients usually seem less severe on admission with smaller weight loss or bradycardia and fewer eating disorder symptoms than anorectic patients, but often have longer hospitalization [16]. ARFID is frequently associated with ASD, especially in ones with strong preferences on the food's sensory qualities. Other comorbid states include pica, anxiety disorders, obsessive-compulsive disorder, attention deficit/hyperactivity, neurodevelopmental and intellectual developmental disorders [1], or gastrointestinal problems, history of food related traumas (e.g., vomiting or choking) and food allergies [15].

In spite of the high prevalence and comorbidiy of ARFID, hardly anything is known about its effective interventions $[14,16]$. The clinical guideline of DSM-V feeding and eating disorders [2] emphasized the lack of specific its treatment recommendations. Eating disorders' researchers are urged to investigate its predisposing factors, standardized assessment instruments, and to evidence effective treatment methods to guide clinical practice [2].

\section{Aims}

The aim was to review the most important risk factors, assessment methods, and chiefly to summarize treatment methods of ARFID to provide guidance in its clinical management and psychotherapy.

\section{Method}

The Review process focused on the literature since the introduction of ARFID. As its term was first mentioned in 2012 [e.g., 17], this systematic review was conducted with dates 2012-2015 to identify and synthesize relevant studies. The search was carried out with Pub Med and Web of Science databases using the key words of 'avoidant restrictive food intake disorder', resulting in 36 papers in Pub Med, 28 papers in Web of Science, and 11 relevant matches in Google Scholar. The PRISMA flow algorithm [18] was applied to filter the results. Excluding the duplicates and non relevant matches, 29 papers were found about the exact topic to summarize the risk, assessment and treatment-related findings.

\section{Results and Discussion}

Risk factors of ARFID

The background of food avoidance or restricted intake in ARFID is deeply diverse [14], and on the basis of its underlying traits several risk factors can be highlighted:

1. The child's temperament, neurodevelopment or intellectual impairments (e.g., ASD, attention deficits) can reduce the responsiveness to eating and feeding [1,21]. However, selective eating can occur with and without background developmental disabilities $[22]$. 
2. In children restriction is based on the food's sensory characteristics in up to $60.9 \%$ of the cases $[8,11]$; which is mostly associated with autism spectrum disorders or pica [1].

3. Other psychological or psychiatric disorders can also pose risk for ARFID [14]. Emotional difficulties, anxiety disorders, depressive or bipolar symptoms, obsessive-compulsive traits, can trigger food avoidance or selective eating, especially in older children or adolescents $[1,3]$.

4. Food avoidance is often originated from conditioned negative response after aversive experiences like choking or vomiting [14] in up to $15.2 \%$ of the cases [11].

5. In some patients food avoidance or restriction can be maintained by the lack of interest in eating [11], or with the lack of communication of hunger [1].

6. Physiological conditions like gastrointestinal problems (e.g., reflux) can increase the risk of food avoidance or restriction [14]. Although ARFID should not be exclusively ascribed to a concurrent medical condition [12].

7. Familial anxiety, parent-child interactional deficiencies owing to the parent's psychopathology (e.g., the mother's eating disorder) or misinterpreting the infant's behavior can also contribute to the development or maintenance of the disorder [1]. Mothers of children with feeding disorders are usually unpredictable, overcontrolling, intrusive, more punishing, angry and hostile, less affectionate, less flexible or accepting, often force feeding, and have difficulties in recognizing the child's emotions [8,23]. Caregivers often had eating or personality disorders, depression, anxiety, or other mental health problems $[8,24]$. The risk factors of ARFID and avoidant / restrictive eating are shown in Table 1. 
Table 1. Risk factors of ARFID and avoidant or restrictive eating

\begin{tabular}{lrr}
\hline Risk / background factors & Frequency* & Reference \\
\hline $\begin{array}{l}\text { Avoidance based on the sensory properties of the } \\
\text { food (often associated with ASD) }\end{array}$ & $60.9 \%$ & {$[1,11,21,22,25]$} \\
$\begin{array}{l}\text { Anxiety disorders (e.g. generalized anxiety or obses- } \\
\text { sive-compulsive traits) }\end{array}$ & $21.4-58 \%$ & {$[1,3,15,21,22]$} \\
$\begin{array}{l}\text { Lack of interest in eating or the lack of communica- } \\
\text { tion of hunger }\end{array}$ & $39.1 \%$ & {$[1,11]$} \\
$\begin{array}{l}\text { Eating problems prior to the first 18 month like se- } \\
\text { lective eating or feeding since early childhood }\end{array}$ & $28.7 \%$ & {$[15,22]$} \\
$\begin{array}{l}\text { Gastrointestinal symptoms (e.g., gastroesophageal } \\
\text { reflux) }\end{array}$ & $19.4 \%$ & {$[1,14,15]$} \\
$\begin{array}{l}\text { Mood disorders (e.g., depressive or bipolar symp- } \\
\text { toms) }\end{array}$ & $19 \%$ & {$[1,3]$} \\
$\begin{array}{l}\text { Negative consequences or posttraumatic stress dis- } \\
\text { order related to eating/feeding or direct history of } \\
\text { choking/vomiting }\end{array}$ & $13.2-15.2 \%$ & {$[1,11,15,25]$} \\
$\begin{array}{l}\text { Food allergies } \\
\text { Child's other psychopathologies (e.g., attention def- } \\
\text { icit, infantile anorexia) }\end{array}$ & no data & {$[1,21,25]$} \\
$\begin{array}{l}\text { Caregiver's psychopathology (e.g. eating disorders, } \\
\text { personality disorder, depression, anxiety) }\end{array}$ & no data & {$[1,7,8,24,26]$} \\
$\begin{array}{l}\text { Interactional problems related to eating, forced feed- } \\
\text { ing (e.g. unpredictable, overcontrolling, hostile care- } \\
\text { giver, difficulties in recognizing the child's signals } \\
\text { and satiety) }\end{array}$ & no data & {$[1,8,9,23,27]$} \\
\hline
\end{tabular}

Note: Percent of patients presenting the symptoms of avoidant/restrictive eating.

\section{Assessment methods of AFRID}

There are no standardized and formalized measures to assess the diagnostic and exclusion criteria of ARFID [2,5]. However, structured DSM-V diagnostic interviews, two questionnaires $[28,31]$ with the most important symptoms, and a diagnostic guideline [19] can be found that supports the assessment of ARFID.

The structured DSM-V interview $[1,4]$ may mean the most important current assessment method, including the child's observation and parental anamnesis. The measurement of the related nutritional deficiency - the most severe accompanying symptom - can be based on clinical assessment including the laboratory tests, physical examination (e.g., hypothermia, bradycardia, anemia) and the assessment of dietary restraint. Bryant-Waugh et al. [8,19] suggested clinicians applying four dimensions to assess the severity of 
childhood food avoidance/restriction: 1. the nutritional adequacy of the diet. 2 . The impact of the disorder on weight, growth, and physical development. 3. Influence on social and emotional development. (4) Related disturbances in caregiver interactions and family function. These require special attention the interview-based assessment of AFRID.

The Children's Eating Disorder Examination-Questionnaire (ChEDEQ; $[28,29]$ is a self-report measure derived from the Eating Disorder Examination interview [29], assessing eating-disorder attitudes and behaviors in children and adolescents in four subscales: Restrained Eating, Weight Concern, Shape Concern, and Eating Concern. Higher scores on the scales reflect more pathological concerns. The ChEDE-Q has good psychometric qualities $(.82<$ Cronbach's alpha< .94) [30]. The ChEDE-Q is a useful standardized measure of ARFID, as it assesses restricted eating pattern and its exclusion criteria [11].

The Eating Disturbances in Youth-Questionnaire (EDY-Q) [31] is a 14 item instrument that perfectly represents the DSM-V diagnostic criteria of ARFID and other early-onset restrictive eating disorders [11]. Items refer to emotional and sensory food avoidance, avoidance of new foods, interest in food, selective eating, dysfunctional dysphagia including fear of chocking or swallowing, underweight and desire to gain weight. The EDY-Q also contains the exclusion criteria of weight and shape concerns. Items can be rated on a Likert-type scale from never ( Kurz and colleagues [11] ARFID was fulfilled when the frequency of each eating behavior was reported as at least 'often' (cut-off $\geq 4$ ). Exclusion criteria needed to be reported less than "sometimes" (cut-off $<3$ ). EDY-Q had good validity, but their factors seem to have low internal consistencies $(.42 \leq$ Cronbach's alpha $\leq .52)[11,32]$.

Bryant-Waugh [19] offered a guideline about the specific information need in course of the diagnostic interviews, and suggested to clarify the following questions:

1. What is the current range and amount of food intake? This can establish, whether the patient fails the required nutritional and energy needs.

2. How long has the restriction or avoidance been occurring? This establishes, whether this is a persistent matter.

3. Has the current weight and height been dropped compared to the expected centiles? This establishes faltering growth and the failure to gain as it would be expected for current age.

4. Can we observe any signs of nutritional deficiency or malnutrition? To establish the evidence of clinical nutritional deficiency.

5. Do we need to supplement the child's intake to ensure its adequate level? To establish the dependence on nutritional supplements or tube feeding. 
6. Is this eating pattern associated with distress or interference with the daily functioning? To establish the eating disturbance's interference with the social or emotional functioning.

7. Furher questions should certify the exclusion criteria like the lack of availability of food, social and cultural practices, or body image disorder including weight and shape concerns.

Although, no consistent evidences refer to the discrete subtypes of ARFID and its clinical representations are not always mutually exclusive [1], Bryant-Waugh [19] suggested three different clusters of patients: a. restriction related to the lack of interest in food, $b$. sensory-based avoidance, and c. avoidance based on the threatening consequences of eating. Perhaps these subtypes shall be differentiated in the diagnostics to optimize treatment choice.

\section{Treatment methods of ARFID}

\section{Nutritional management}

As underweight, nutritional deficiency and dependence supplements are determining features of ARFID, medical and nutritional management seem to be central in its treatment. The primary aim of each ARFID treatment is to minimize the patient's physical risk and to normalize their body weight $[15,19]$. A thorough examination might determine how far the patients' maladaptive behavior is explained by medical conditions [33]. Several authors [e.g., $15,34,35]$ applied nutritional management as a substatnital part of the treatment, including supplements, vitamins, nutri drinks, calcium or probiotics. In the study of Strandjord and colleagues [16] medical management included dietary prescriptions of 1500-2200 calories adjusted to a .2 kg of weight gain per day, balanced with nutri drinks, if refused via nasogastric tube. Patients needed to undertake continuous cardiorespiratory monitoring with bed rest, complete metabolic laboratory panels and received phosphorus supplementation. Nutritional management can be combined with pharmacotherapy and psychotherapies $[19,36]$, and may also hold potentials to shape eating behavior. As sensory properties of the food often trigger the avoidant behavior [11] changing the food's sensory properties or the attitude towards them holds therapeutic potentials [14]. The lack of interest in food intake is also an essential factor [11] that might be modified through the environmental, emotional or motivational aspects of the feeding process, suggesting that therapeutic interventions are strongly related to the simple changes of the nutritional process.

\section{Behavior and cognitive-behavior therapy}

As food avoidance is the central trait of ARFID, thus Kenney and Walsh [14] supposed that behavioral interventions like specified forms of exposure therapy can be effective. Patients can respond well to standard treatments of phobias [34]. Behavior therapy techniques can include systematic desensitization, gradual exposure to the aversive stimuli, and the management of the associated anxiety. Introducing new foods with similar sensory qualities 
to the accepted ones was suggested by Bryant-Waugh $[8,19]$. Broadening the restricted nutritional range and eating pattern with similar then gradually changing food seems be central in the treatment of ARFID [14,34]. Changing the avoidant behavior by the modifying the range of accepted foods, increasing bite sizes or time of meals [e.g., 20], and other shaping strategies serve as general step of specific behavioral interventions. While observing emotions and interactions related to eating may show useful information to other psychological interventions. The only intervention-based, randomized pilot trial about an intensive, manualized behavioral treatment of ARFID was published by Sharp and colleagues [20]. This contained 14 treatment meal sessions in five consecutive days with twenty 1-6-year-old participants. Children were presented one out of 8 pureed foods. When the child swallowed the food at stable rates bite volume was gradually increased. Based on Sharp and colleagues [37] structured parental trainings were added in meal 12 and 13. By meal 14, parents fed their children; with the therapist's feedbacks, if needed. This was supported with a manual-based behavioral feeding intervention (integrated Eating Aversion Treatment; iEAT) containing: a. data collection about mealtime performances (e.g., bite acceptance, crying, disruptions), b. automatic data analysis, c. behavioral treatment focusing on escape extinction, reinforcement procedures, and formalized meal structure (e.g., scripted instructions, reduced bites, pureed food texture). Patients showed significant increase in accepted bites and volume of food with slight increase in BMI-percentiles that was stable in one month follow-up [20].

When emotional factors like severe anxiety associated with eating strongly contribute to the maintenance of the disorder [e.g., 3, 15] cognitive behavior therapy (CBT) can be a useful intervention method [14]. However, authors of present paper would like to emphasize that the use of cognitive methods can be highly dependent upon the age and cognitive development of the patients, suggesting the expedience of CBT in adolescent and adult ARFID patients. Bryant-Waugh [19] implemented CBT in smaller well-defined targets, combined with parental involvement. The therapy aimed to increase the patient's responsibility for own health through addressing nutritional risk. Core CBT interventions included: 1. self-monitoring, 2. cognitive restructuring, 3. behavioral experiments, and 4. relaxation methods. Behavioral experiments like the introduction of new foods with similar sensory characteristics were supported in the CBT by anxiety management skills such as breathing and progressive muscle relaxation. King, Urbach and Stewart [38] presented a case of a women suffering from illness anxiety [1] and ARFID with anxietybased avoidance. The patient was successfully treated with CBT that involved: 1. psychoeducation about the physical symptoms of anxiety that can be misinterpreted as signs of illness or choking causing catasrophization and hypervigilance. Avoidance of eating was interpreted as a maladaptive anxiety reducing strategy. 2. Cognitive restructuring was used to identify evidences against 
catastrophic beliefs and sensations with the rating of possibility of catastrophic consequences. 3. Systematic desensitization consisted of in-vivo exposures during meal times, based on a hierarchy of feared foods from "safe" to "unsafe". This aimed to increase the amount, variety and bites of food eaten. Subjective level of anxiety was rated from 1 (none) to 10 (extreme). 4. Relaxation techniques were also implemented to help cope with anxiety.

\section{Self-regulation and anxiety management techniques}

Kreipe and Palomaki [34] presented a case of a 14-year-old male athlete with sensory-based food aversion that generating anxiety. Treatment was based on guided imagery self-relaxation exercises prior to eating. This approach was supported with nutritional counseling and Fluoxetine intake. The patient could increase the variety of foods, gained back normal weight, and felt mastering the emotional responses, although some residual sensory symptoms remained. Repeated imagination of the avoided food means internal exposure, and self-relaxation helps decreasing anxiety, therefore this approach can be interpreted as a systematic desensitization. In another case of Kreipe and Palomaki [34] a 10-year-old girl had almost choked from food, thus she became unwilling to try new foods and insisted on having only smooth foods. This resulted to conditioned involuntary spasm of her esophagus, and she lost weight as well. Biofeedback was offered her demonstrating that she was able to gain control over conditioned responses. This encouraged her to increase self-regulation to master the involuntary muscle responses of her esophagus. Supportive therapy was applied to ventilate her chocking experience. She experienced success in swallowing different foods, and gained confidence after four sessions. Techniques like imagination, relaxation and biofeedback can be realized in course of the CBT $[19,36]$, and seemed supporting patients to recover their ability of self regulation.

\section{Family therapy and family based treatment (FBT)}

According to our own clinical experiences, if any childhood eating disorder is present, patients receive greater attention with the emergence of the sick role, familiar dependence or the pressure of eating also increases. When the child rejects eating, parents, most often mothers may perceive that their parental roles are questioned. This can increase parental stress, and influence patents' attitude towards eating by indicating anxiety or anger that may start a negative spiral which can fortify the child's food refusal. This negative spiral can be interrupted by involving the parents in the treatment. Thus, parents and often the broader social environment (e.g., kindergarten, school) should be involved in the treatment of child ARFID patients. Lopes and colleagues [36] reinforces that parents shall be involved in the treatment plan. Family members need to have psychoeducation about the illness course and the expected reinforcement strategies of the child's healthy behavior [38]. In other cases, higher involvement of the families can be suspected; several childhood feeding 
disorders can be defined as relational disorders [9]. More authors [e.g., 8,19] emphasized the child's and the caregivers' characteristics, their relationship's deficiencies and the nutritional context can all contribute to the feeding and eating pathology. The primary international treatment recommendation for young patients with anorexia nervosa is family therapy [2,39]. Considering similar characteristics of ARFID and anorectic patients such as weight loss, restricted eating pattern, avoidance of certain foods, childhood or teenager onset, the utility of family-based treatments can be suspected in cases where interactional or parental dysfunctions contribute to the disorder. However, Thomas and colleagues [40] suggested different approaches in anorectic and ARFID patients. Forman and colleagues [15] found that family based treatments were used in $38 \%$ of the patients with restrictive eating disorders, and were just as effective in weight restoration as individual or other medical treatment methods. According to Norris and colleagues [35] all ARFID patients were successfully re-nourished and progressed with a psychological treatment that focused on anxiety and feeding management in a family-based treatment model. Lopes and colleagues [36] directly emphasized the involvement of the family as an essential element of the successful treatment in child and adolescent ARFID patients. When interactions contribute to the disorder, or when individuation from the family is needed FBT can be indicated alone or combined successfully with the other individual treatment modalities $[15,19,35,41]$.

\section{Pharmacotherapy}

When mood or anxiety disorders contribute to ARFID symptoms the use of pharmacotherapy can be suspected as a supplementary therapeutic method. In some case studies medicines used for depression or anxiety disorders like selective serotonin reuptake inhibitors (SSRIs) or benzodiazepines were used as a part of the complex treatment of ARFID [e.g., 35, 36]. Fluoxetine (SSRI) was used beside the psychotherapy to treat sensory-based food avoidance with comorbid anxiety [34]. SSRIs were efficiently used in childhood chocking phobia [35]. However, evidences for the efficacy of pharmacotherapy methods in ARFID are lacking [33], and Norris and colleagues [36] referred on its lower efficacy. While Lopes and colleagues [37] used it efficiently combined with various methods of CBT. Therefore the combination of pharmacotherapy with psychotherapy can be rather supported, but specific medication definitely needs to be tested by further clinical studies.

\section{Combined treatments}

Lopes and colleagues [37] presented an adult AFRID patient suffered from chocking phobia treated with combined treatment included pharmacotherapy (SSRIs), nutritional management, psychoeducation about consequences of nutritional deficiency and treatment goals. CBT was also 
implemented with three aims: (1) cognitive restructuring as cognitive distortions lead to generalized avoidance behavior. (2) Anxiety management. (3) Desensitization with gradual exposure therapy, through small well defined intermediate goals of exposing foods such as approaching to the feared food, gradually increased bite sizes and reduced chewing, accompanied with breathing and relaxation techniques. Bryant-Waugh [19] emphasized that necessity of treatments that commonly include medical intervention, nutritional management and psychotherapies. Most case studies generally reflect a CBT approach with restructuring of the avoidant cognitive distortions, gradual exposure of the feared stimuli, changing eating patterns and introduction of new foods, combined with anxiety management like progressive relaxation $[11,14,19,37]$. In child and adolescent ARFID patients the parents' involvement in the treatment plan and psychoeducation is essential [37,38]; and a successful family-based treatment can be combined with anxiety and feeding management [36]. Chandran and colleagues [43] referred a case about a 17year-old mage ARFID patient with selective eating since many years with comorbid subacute spinal cord degeneration managed with combined inpatient treatment: 1. standard inpatient eating disorder treatment. 2. Nasogastric feeding. 3. Varied diet with supplements. 4. Pharmacotherapy (Quetiapine). 5. Routine psychotherapy for anxiety management. 6. Family therapy was also applied to help the individuation process. 7. Individual psychotherapy supported the outpatient management. The evidence-based treatment methods of ARFID are shown in Table 2. 
Table 2. Applied therapy methods in ARFID

\begin{tabular}{|c|c|c|c|c|}
\hline $\begin{array}{l}\text { Therapy } \\
\text { method }\end{array}$ & Main intervention & Indication & Efficacy & Reference \\
\hline $\begin{array}{l}\text { Nutritional } \\
\text { management }\end{array}$ & $\begin{array}{l}\text { Nutritional } \\
\text { supplements, } \\
\text { vitamins, } \\
\text { nutri drinks, } \\
\text { calcium, probiotics }\end{array}$ & $\begin{array}{l}\text { Most cases: } \\
\text { undernourished, low } \\
\text { body weight }\end{array}$ & $\begin{array}{l}\text { No data; } \\
\text { part of } \\
\text { weight } \\
\text { restoration }\end{array}$ & $\begin{array}{r}{[15,16,19,} \\
34,36,37]\end{array}$ \\
\hline Psychoeducation & $\begin{array}{l}\text { Treatment step and } \\
\text { goals, consequences } \\
\text { of nutritional } \\
\text { deficiency, } \\
\text { symptoms' } \\
\text { misinterpretations, } \\
\text { psychoeducation } \\
\text { for family members }\end{array}$ & $\begin{array}{l}\text { General / } \\
\text { anxiety / } \\
\text { experiencebased } \\
\text { avoidance }\end{array}$ & $\begin{array}{l}\text { No data; } \\
\text { part of CBT } \\
\text { and FBT }\end{array}$ & {$[37,40]$} \\
\hline \multirow[t]{4}{*}{$\begin{array}{l}\text { Behavior } \\
\text { therapy and CBT }\end{array}$} & $\begin{array}{l}\text { Standard phobia } \\
\text { treatments, gradual } \\
\text { exposure therapy } \\
\text { (often } \\
\text { combined with } \\
\text { other modalities) }\end{array}$ & $\begin{array}{l}\text { Anxiety or } \\
\text { sensory-based } \\
\text { avoidance/ } \\
\text { restriction, } \\
\text { aversive } \\
\text { experiences, chock- } \\
\text { ing phobia }\end{array}$ & $\begin{array}{l}\text { Good; most } \\
\text { often used }\end{array}$ & $\begin{array}{r}{[11,14,19,} \\
20,37]\end{array}$ \\
\hline & $\begin{array}{l}\text { Behavioral experi- } \\
\text { ments (e.g., intro- } \\
\text { duction of new } \\
\text { foods with similar } \\
\text { sensory features) }\end{array}$ & $\begin{array}{l}\text { Sensory-based re- } \\
\text { striction, negative } \\
\text { experiences or emo- } \\
\text { tions } \\
\text { related to eating }\end{array}$ & Often used & {$[8,19]$} \\
\hline & $\begin{array}{l}\text { Changing } \\
\text { sensory qualities of } \\
\text { the food or } \\
\text { the patient's attitude }\end{array}$ & $\begin{array}{l}\text { Lack of interest in } \\
\text { eating or sensory- } \\
\text { based avoidance }\end{array}$ & No data & {$[14,34]$} \\
\hline & $\begin{array}{l}\text { Self-monitoring, nu- } \\
\text { tritional risk assess- } \\
\text { ment, increasing re- } \\
\text { sponsibility, } \\
\text { cognitive restructur- } \\
\text { ing, invivo - and in- } \\
\text { teroceptive exposi- } \\
\text { tions, systematic } \\
\text { desensitization with } \\
\text { anxiety } \\
\text { management }\end{array}$ & $\begin{array}{l}\text { Aversive } \\
\text { food-related experi- } \\
\text { ences, emotional } \\
\text { factors contribute to } \\
\text { avoidance } \\
\text { or restriction, chock- } \\
\text { ing } \\
\text { and vomiting } \\
\text { phobia }\end{array}$ & $\begin{array}{l}\text { good; } \\
\text { often used or } \\
\text { combined } \\
\text { with } \\
\text { other } \\
\text { methods }\end{array}$ & $\begin{array}{r}{[14,19,} \\
37,40,44]\end{array}$ \\
\hline \multirow[t]{2}{*}{$\begin{array}{l}\text { Self-regulation } \\
\text { and anxiety } \\
\text { management: } \\
\text { relaxation, } \\
\text { imagination, bio- } \\
\text { feedback }\end{array}$} & $\begin{array}{l}\text { Breathing and pro- } \\
\text { gressive relaxation } \\
\text { techniques, guided } \\
\text { imagery selfrelaxa- } \\
\text { tion prior to eating } \\
\text { (parts of the CBT or } \\
\text { desensitization) }\end{array}$ & $\begin{array}{l}\text { Aversive experi- } \\
\text { ences, } \\
\text { anxious, } \\
\text { phobic or sensory- } \\
\text { based food aversion } \\
\text { / avoidance }\end{array}$ & $\begin{array}{l}\text { Partial; } \\
\text { part of } \\
\text { desensitiza- } \\
\text { tion }\end{array}$ & $\begin{array}{r}{[19,34,} \\
37,40]\end{array}$ \\
\hline & $\begin{array}{l}\text { Biofeedback, } \\
\text { self-regulation } \\
\text { xercises }\end{array}$ & $\begin{array}{l}\text { Traumatic } \\
\text { experiences with } \\
\text { food, phobias }\end{array}$ & Good & [34] \\
\hline
\end{tabular}




\begin{tabular}{|c|c|c|c|c|}
\hline $\begin{array}{l}\text { Family-based } \\
\text { treatment }\end{array}$ & $\begin{array}{l}\text { Changing feeding } \\
\text { and interactional } \\
\text { patterns, } \\
\text { anxiety and feeding } \\
\text { management, } \\
\text { supporting } \\
\text { individuation, } \\
\text { reinforcements } \\
\text { of healthy behavior }\end{array}$ & $\begin{array}{l}\text { Feeding anxiety, } \\
\text { deficient interac- } \\
\text { tions, pressure } \\
\text { to eat parents' } \\
\text { pathology, need } \\
\text { for individuation }\end{array}$ & $\begin{array}{l}\text { Good or as } \\
\text { efficient as } \\
\text { other } \\
\text { methods; } \\
\text { parental } \\
\text { involvement } \\
\text { is necessary } \\
\text { in children }\end{array}$ & $\begin{array}{r}{[9,15,36,} \\
40,43]\end{array}$ \\
\hline Pharmacotherapy & $\begin{array}{l}\text { Antidepressants, } \\
\text { SSRIs, } \\
\text { benzodiazepines }\end{array}$ & $\begin{array}{l}\text { contributing emo- } \\
\text { tional factors (e.g., } \\
\text { depression, anxiety) }\end{array}$ & $\begin{array}{l}\text { low; better, } \\
\text { if combined } \\
\text { with } \\
\text { psychother- } \\
\text { apy }\end{array}$ & $\begin{array}{r}{[15,19,} \\
34,35,36]\end{array}$ \\
\hline
\end{tabular}

\section{Predictors of treatment outcome}

The efficacy of the above mentioned therapeutic approaches is heterogeneous, and only reflected from case studies. Most authors have reported about combined treatments, just as the only randomized control pilot trial that have successfully used specific behavioral interventions like gradual exposure combined with parental training [20]. However, Forman and colleagues [15] found that ARFID patients have 2-4-times lower odds for weight restoration than anorectic or atypical anorectic patients; and often have higher drop-out rates because of their different and more complex treatment needs. Males overrepresented in ARFID may have worse treatment responses in settings where they are in minority. The type of intervention was not a significant predictor of treatment outcome without large differences between the pharmacotherapy, nutritional therapy, individual therapy, family based treatment and "higher level of care". According to their results the median body mass index predicted weight restoration, suggesting weight recovery as the primary aspect of any ARFID treatment.

\section{Conclusions}

The manuscript aimed to review the current case reports and studies on the risk factors, assessment facilities, and to synthesize the available information about the treatment of ARFID with the primary goal to draw therapeutic implications.

Multifaceted reasons behind the restricted or avoidant eating pattern suggest using different treatment methods according to the individual background factors. Food refusal can be associated with qualitatively different feeding or eating patterns of diverse origins such as avoidance based on sensory qualities, negative experiences related eating, parental interactions or the lack of interest in eating. Selective food refusal can be originated in sensory food aversion; unpredictable refusal is often related to infantile anorexia nervosa, while fear-based refusal is mostly associated with traumatic feeding [25]. These different subtypes commonly indicate different approaches [25]. The 
various comorbid states of ARFID also require attention in the treatment choice and in the course of the therapies. Kenney and Walsh [14] suggested applying any methods that treat the underlying conditions of ARFID in an evidence-based way. Therefore, the efficacy of heterogenic therapy methods can be suspected in its different presentations [19], suggesting a complex treatment with different modalities that aim to treat each component of the disorder. This suggests distinguishing general and specific treatment recommendations in the different subtypes of ARFID.

\section{General treatment recommendations}

Each therapy of ARFID shall be implemented according to the patients' and their families' individual needs, and should respond to the biopsychosocial aspects of the disorder requiring interdisciplinary approach. Patients require individualized treatment plans according to their complex histories [45]. Exact treatment plans should be set up as soon as possible based on the symptoms' severity, with the primary step to stabilize the severe somatic status [15]. Therapeutic needs can be assessed according to the impact of food avoidance or restriction on nutritional withdraw, the weight loss, growth deficiency, associated distress, and the decrease in social and emotional functioning [19]. Treatment procedures shall start with risk assessment, setting goals, and health- or psychoeducation. Psychoeducation shall focus on both the physical and psychological consequences of ARFID [40]; while most treatments include medical and psychological interventions as well as nutritional advice [46]. As in many cases achieving an eating pattern without any avoidance or restriction is neither realistic nor desirable, therefore therapist should above all aim to minimize the physical or nutritional risk by changing the individuals behavior through anxiety management, trying new foods and extending the dietary intake [19]. Norris and colleagues [36] warned, that some of the ARFID patients are at risk to evolve into AN as treatment progresses, thus therapist must beware of the symptom changes or other implications of the therapy. As except case reports and one pilot trial no exact guidance is available for ARFID, treatment shall be based on most responsible areas for the avoidant or restricted food intake [19]. This may mean that symptom characteristics can be determining in the exact treatment choice beside the primary aim of weight restoration [15]. Most treatment shall necessarily include: 1 . medical monitoring, 2. nutritional management, and 3. psychological interventions [46]. Dependent on the initial presentation of the patient even intensive treatment can be required [5]. However, choosing the right psychotherapeutic intervention and planning its steps seem to be the most complex question in the treatment of ARFID. 


\section{Summary of the most effective treatments of ARFID}

Although no evidence-based treatments could have been identified till the end of 2015; case studies, clinical reports and pilot trials suggest the utility of an individualized combination of: 1. medical treatment with the primary focus on the stabilization of the patient' somatic status. This is often combined with 2. nutritional management and 3. psychotherapeutic interventions $[2,45,46]$. Pharmacotherapy seemed alone less effective in ARFID, or showed heterogeneous results when combined with other modalities, but nutritional management was unavoidable in most of the cases $[15,19,34,36]$. Each treatment that aims to be effective shall fit the patients' and their families individual needs, and should react on the different presentations or subtypes of ARFID with their diverse symptomatic characteristics. This can include: 1. selective eating based on the foods' sensory qualities, 2. avoidance owing to traumatic experiences like in chocking phobia and emetophobia 3. restriction triggered by emotions, 4 . or avoidance because of interactional difficulties $[1,11,14]$. General psychotherapeutic implications are to start the treatment with psychoeducation [40] - if adult for the patient, if child for the parents -, and to involve the parents in the treatment of children [36,41]. The most effective psychotherapy methods can be:

1. Behavior therapy with exposure and systematic desensitization including gradual introduction of new foods in most cases of avoidance, primarily when the restriction is based on the foods sensory qualities $[11,14,19,20,34,37]$.

2. CBT, where the therapeutic process is supported by cognitive restructuring of the irrelaistic consequences of eating, and self-regulation strategies like anxiety management (e.g. biofeedback, breathing or relaxation techniques). CBT can be especially suggested in emotionally triggered restriction (e.g., mood disorders) or avoidance based on traumatic events (e.g., in chocking or vomiting phobia) [14,19,37,40,44].

3. Family based treatments are specially recommended when interactional patterns, familiar reinforcement, parental pathologies or the individuation process shall be supported [15,36,40,43].

4. However, most cases can require combined treatments involving medical (if needed pharmacotherapeutic) care, nutritional management, psychoeducation, and an individualized mixture of specific behavior therapy, CBT and FBT methods $[11,14,19,7,43]$.

\section{Final conclusion and outlook}

This paper shall be read in the light of limitations, as we could only review cases published after the introduction of ARFID, synthesized according to our own clinical experiences; but no interventions were involved to conduct this paper. Authors of this review share the opinion of Norris and Katzman [47], who concluded that studies should start assessing the effectiveness of 
different treatment approaches based on manualized interventions. Longitudinal researches are urged [40] to describe strict evidence-based guidelines for each presentations of ARFID.

Abbreviations

ARFID: Avoidant/Restrictive Food Intake Disorder

ASD: autism spectrum disorder

CBT: cognitive behavior therapy

FBT: family based treatment

SSRI: selective serotonin reuptake inhibitor

\section{Competing interests}

The authors declare that they have no competing interest, and received no financial support to prepare this paper. Present paper is based on the review of literature evidences; no participants were involved to conduct this manuscript.

\section{References}

1. American Psychiatric Association. APA. Diagnostic and statistical manual of mental disorders - Fifth edition. DSM-V. Arlington: American Psychiatric Publishing; 2013.

2. Hay P, Chinn D, Forbes D, Madden S, Newton R, Sugenos L, Touyz S, Ward W. (2014). Royal Australian and New Zealand College of Psychiatrists clinical practice guidelines for the treatment of eating disorders. Aust NZ J Psychiat. 2014;48(11):977-1008.

3. Fisher MM, Rosen DS, Ornstein RM, Mammel KA, Katzman DK, Rome ES, Challahan CS, Malizio J, Kearney S, Walsh BT. Characteristics of avoidant/restrictive food intake disorder in children and adolescents: a "new disorder" in DSM-5. J Adolescent Health. 2014;55(1):49-52.

4. Nussbaum AM. A DSM-V diagnosztikai vizsgálat zsebkönyve. [The pocketbook of DSM-5 diagnostic examination.] Budapest: Oriold és Társai; 2013.

5. Nicely TA, Lane-Loney S, Masciulli E, Hollenbeak CS, Ornstein RM. Prevalence and characteristics of avoidant/restrictive food intake disorder in a cohort of young patients in day treatment for eating disorders. J Eat Disorder, 2014;2,1:21.

6. Zucker N, Copeland W, Franz L, Carpenter K, Keeling L, Angold A, Egger H. Psychological and psychosocial impairment in preschoolers with selective eating. Pediatrics. 2015;136(3):582-90.

7. Patrick H, Nicklas TA, Hughes SO, Morales M. (2005). The benefits of authoritative feeding style: caregiver feeding styles and children's food consumption patterns. Appetite. 2005;44(2):243-9.

8. Bryant-Waugh R, Markham L, Kreipe RE, Walsh BT. Feeding and eating disorders in childhood. Int J Eat Disorder. 2010;3,2:98-111.

9. Davies WH, Satter E, Berlin KS, Sato AF, Silverman AH, Fischer EA, Arvedson JC, Rudolph CD. Reconceptualizing feeding and feeding 
disorders in interpersonal context: The case for a relational disorder. J Fam Psychol. 2006;20(3):409-17.

10. Ornstein RM, Rosen DS, Mammel KA, Callahan ST, Forman S, Jay MS, Walsh BT. Distribution of eating disorders in children and adolescents using the proposed DSM-5 criteria for feeding and eating disorders. J Adolescent Health. 2013;53(2):303-5.

11. Kurz S, Van Dyck Z, Dremmel D, Munsch S, Hilbert A. (2014). Earlyonset restrictive eating disturbances in primary school boys and girls. Eur Child Adoles Psy. 2014;24(7):79-85.

12. Williams KE, Hendy HM, Field DG, Belousov Y, Riegel K, Harclerode W. Implications of Avoidant/Restrictive Food Intake Disorder (ARFID) on children with feeding problems. Child Health Care. 2012;44(4):30721.

13. Eddy KT, Thomas JJ, Hastings E, Edkins K, Lamont E, Nevins CM, Becker AE. Prevalence of DSM-5 avoidant/restrictive food intake disorder in a pediatric gastroenterology healthcare network. Int J Eat Disorder. 2014;48(5):464-70.

14. Kenney L, Walsh T. Avoidant/Restrictive Food Intake Disorder (ARFID). Defining ARFID. Eat Disord Rev. 2013;24,3:1-4.

15. Forman SF, McKenzie N, Hehn R, Monge MC, Kapphahn CJ, Mammel KA, Woods ER. Predictors of outcome at 1 year in adolescents with DSM-5 restrictive eating disorders: Report of the national eating disorders quality improvement collaborative. J Adolescent Health. 2014;55(6):750-6.

16. Strandjord SE, Sieke EH, Richmond M, Rome ES. Avoidant/Restrictive Food Intake Disorder: illness and hospital course in patients hospitalized for nutritional insufficiency. J Adolescent Health. 2015;57(6):6738.

17. Uher R, Rutter M. Classification of feeding and eating disorders: review of evidence and proposals for ICD-11. World Psychiat. 2012;11(2):8092.

18. Moher D, Liberati A, Tetzlaff J, Altman DG, The PRISMA group. Preferred reporting items for systematic reviews and meta-analyses: The PRISMA statement. Ann Intern Med. 2009;151:264-9.

19. Bryant-Waugh R. Avoidant restrictive food intake disorder: An illustrative case example. Int J Eat Disorder. 2013;46(5):420-3.

20. Sharp WG, Stubbs KH, Adams H, Wells BM, Lesack RS, Criado KK, Scahill LD. Intensive, manual-based intervention for pediatric feeding disorders: results from a randomized pilot trial. J Pediatr Gastr Nutr. 2015; doi: 10.1097/MPG.0000000000001043.

21. Timimi S, Douglas J, Tsiftsopoulou K. Selective eaters: a retrospective case note study. Child Care Hlth Dev. 1997;23(3):265-78.

22. Williams KE, Gibbons BG, Schreck KA. Comparing selective eaters with and without developmental disabilities. J Dev Phys Disabil. 2005;17(3):299-309.

23. Ammaniti M, Ambruzzi AM, Lucarelli L, Cimino S, D’Olimpio F. Malnutrition and dysfunctional mother-child feeding interactions: clinical assessment and research implications. J Am Coll Nutr. 2004;23(3):259-71. 
24. Coulthard H, Harris G. Early food refusal: the role of maternal mood. J Reprod Infant Psych. 2003;21(4):335-45.

25. Chatoor I, Ganiban J. Food refusal by infants and young children: diagnosis and treatment. Cogn Behav Prac. 2003;10(2):138-46.

26. Whelan E, Cooper PJ. The association between childhood feeding problems and maternal eating disorder: a community study. Psychol Med. 2000;30,01:69-77.

27. Chatoor I, Loeffler C, McGee M, Menvielle E. (Eds.). Observational Scale for Mother-Infant Interaction During Feeding. Manual, $2^{\text {nd }}$ edition. Washington DC: Children's National Medical Center; 1998.

28. Fairburn CG, Beglin SJ. Assessment of eating disorders. Int J Eat Disorder. 1994;16(4):363-70.

29. Bryant-Waugh RJ, Cooper PJ, Taylor CL, Lask BD. (1996). The use of the eating disorder examination with children: A pilot study. Int J Eat Disorder. 1996;19(4):391-7.

30. Van Durme K, Brae C, Goossens L. Insecure attachment and eating pathology in early adolescence: role of emotion regulation. J Early Adolescence. 2014; doi: 10.1177/0272431614523130.

31. Van Dyck Z, Bellwald L, Kurz S, Munsch S, Hilbert A. Essprobleme im Kindesalter: Screening in der allgemeinen Bevolkerung. [Eating disturbances in childhood. Screening in the general population]. Z Gesundh. 2013;21(2):91-100.

32. Kurz S, Van Dyck Z, Dremmel D, Munsch S, Hilbert A. Variants of early-onset restrictive eating disturbances in middle childhood. Int J Eat Disorder. 2015; doi: 10.1002/eat.22461.

33. Kelly NR, Shank LM, Bakalar JL, Tanofsky-Kraff M. Pediatric feeding and eating disorders: current state of diagnosis and treatment. Curr Psychiatry Rep. 2014;16(5):1-12.

34. Kreipe RE, Palomaki A. Beyond picky eating: Avoidant/restrictive food intake disorder. Curr Psychiatry Rep. 2012;14(4):421-31.

35. Banerjee SP, Bhandari RP, Rosenberg DR. Use of low-dose selective serotonin reuptake inhibitors for severe, refractory choking phobia in childhood. J Dev Behav Pediatr. 2005;26(2):123-7.

36. Norris ML, Robinson A, Obeid N, Harrison M, Spettigue W, Henderson K. Exploring avoidant/restrictive food intake disorder in eating disordered patients: A descriptive study. Int J Eat Disorder. 2014;47(5):495-9.

37. Lopes R, Melo R, Curral R, Coelho R, Roma-Torres A. A case of choking phobia: towards a conceptual approach. Eat Weight Disord-St. 2014;19(1):125-31.

38. Torralbas-Ortega J, Punti-Vidal J, Valls-Ibanez MV, Arias-Nunez E, Naranjo-Diaz MC. [Choking phobia: care plan in children and adolescents.] Enferm Clin. 2012;22(4):224-23.

39. Sharp WG, Jaquess DL, Morton JF, Miles AG. A retrospective chart review of dietary diversity and feeding behavior of children with autism spectrum disorder before and after admission to a day-treatment program. Focus Autism Other Dev Disabl. 2011;26(1):37-48. 
40. King LA, Urbach JR, Stewart KE. Illness anxiety and avoidant/restrictive food intake disorder: Cognitive-behavioral conceptualization and treatment. Eat Behavior. 2015;(19):106-9.

41. National Collaborating Centre for Mental Health. Eating Disorders: Core interventions in the treatment and management of anorexia nervosa, bulimia nervosa and related eating disorders. London: British Psychological Society; 2004.

42. Thomas JJ, Eddy KT, Murray HB, Tromp MD, Hartmann AS, Stone MT, Becker AE. The impact of revised DSM-5 criteria on the relative distribution and inter-rater reliability of eating disorder diagnoses in a residential treatment setting. Psychiat Res. 2015;229(1):517-23.

43. Chandran JJ, Anderson G, Kennedy A, Kohn M, Clarke S. Subacute combined degeneration of the spinal cord in an adolescent male with avoidant/restrictive food intake disorder: A clinical case report. Int $\mathrm{J}$ Eat Disorder. 2015;48(8):1176-9.

44. Baijens LW, Koetsenruijter K, Pilz W. Diagnosis and treatment of phagophobia: a review. Dysphagia. 2013;28(2):260-70.

45. Lock J. An update on evidence-based psychosocial treatments for eating disorders in children and adolescents. J Clin Child Adolesc. 2015;44(5):707-21.

46. Katzman DK, Stevens K, Norris M. Redefining feeding and eating disorders: What is avoidant/restrictive food intake disorder? Paediatr Child Healt. 2014;19(8):445.

47. Norris ML, Katzman DK. Change is never easy, but it is possible: reflections on Avoidant/Restrictive Food Intake Disorder two years after its introduction in the DSM-5. J Adolescent Health. 2015;57(1):8-9.

Tamás Dömötör SZALAI, Semmelweis University, Institute of Behavioural Sciences, 1089 Budapest, Nagyvárad tér 4., Hungary

E-mail: szalai.domotor@gmail.com 